\title{
Patient Demographics, Perioperative Testing, and Symptom Management in Total Pancreatectomy with Islet Autotransplantation: A Brief Review
}

Claire L. DeBolt ${ }^{1 \#}$, Joshua S. Jolissaint ${ }^{1 \#}$, Jacob A. Tatum ${ }^{1}$, Daniel S. Strand ${ }^{2}$, Andrew Y. Wang ${ }^{2}$, Victor Zaydfudim ${ }^{1}$, Reid B. Adams ${ }^{1}$ and Kenneth L. Brayman ${ }^{1^{*}}$

${ }^{1}$ Department of Surgery, University of Virginia Health System, Charlottesville, Virginia

${ }^{2}$ Division of Gastroenterology and Hepatology, University of Virginia Health System, Charlottesville, Virginia

\#Authors contributed equally

\begin{abstract}
Background

Chronic pancreatitis and its resultant pain, glandular dysfunction, and detriment to quality of life is a challenging and resource-intensive problem for health care systems despite the plethora of modalities developed to treat it. Removal of the gland and source of pain via total pancreatectomy is an effective, albeit drastic solution, with the potential for morbidity due to the complete loss of endocrine and exocrine function. The consequent "brittle diabetes" due to loss of endocrine function and glucagon-dependent counter-regulation may be ameliorated by autologous islet transplantation. Unfortunately, factors leading to optimal outcomes are poorly defined.
\end{abstract}

\section{Results}

Data is mixed and limited to case series from institutions currently performing the procedure, but factors predictive of islet cell yields and overall insulin-independence include: disease etiology, metabolic status, and duration and severity of the disease. Imaging studies may prove an appropriate method for determination of pancreatic volume and disease complications prior to operative intervention. Although potentially overlooked, the resultant malabsorptive diarrhea, traditionally treated with pancreatic enzyme replacement therapy, is a significant barrier to postoperative quality of life and still requires further research and investigation.

\section{Discussion}

Total pancreatectomy with autologous islet transplantation is a proven and effective method for treating those with intractable pain from chronic pancreatitis, but remains barred from widespread use due to cost, limited availability, and potential morbidity. Though great advances have been made, additional efforts at perioperative optimization, appropriate candidate selection and time to intervention must still be sought to further improve post-operative outcomes.

Keywords: Pancreatitis; Chronic; Pain management; Pancreatectomy; Transplantation; Autologous

Abbreviations:BSA: Body Surface Area; CP: Chronic Pancreatitis; CT: Computed Tomography; FSIVGTT: Fasting Sample Intravenous Glucose Tolerance Testing; HbA1c: Glycosylated Hemoglobin A1c; IAT: Islet Autotransplantation; IEQ: Islet Equivalent; IEQ/kg: Islet Equivalent per kilogram Recipient Body Weight; MMTT: Mixed Meal Tolerance Test; SMRCP: Secretin-enhanced Magnetic Resonance Cholangiopancreatograophy; MRI: Magnetic Resonance Imaging; PERT: Pancreatic Enzyme Replacement Therapy; ROC: Receiver Operating Characteristic; TP: Total Pancreatectomy; TPIAT: Total Pancreatectomy with Islet Autotransplantation; QoL: Quality of Life

\section{Introduction}

Chronic pancreatitis (CP) is a debilitating condition characterized by progressive pancreatic inflammation, impairment of endocrine and exocrine function, abdominal pain, reduced Quality of Life (QoL), and increased health resource utilization [1,2]. Although patients can be managed with lifestyle changes, medical and endoscopic intervention, and neural blockade, surgical therapy is occasionally indicated for severe disease [3]. For patients without a single anatomical cause or disease refractory to prior operative interventions, total pancreatectomy (TP) provides definitive treatment and substantial long-term pain relief [4]. First employed in 1977 at the University of Minnesota, islet autotransplantation (IAT) has been employed to preserve $\beta$-cell function and combat the "brittle diabetes" resulting from the loss of both endocrine function and glucagon-dependent counter-regulation [5]. Although there is substantial potential benefit and demonstrated improved long-term outcomes, outcomes, such as insulin and narcotic independence are variable (Table 1) and perioperative and patientrelated factors associated with ideal outcomes are poorly defined.

\section{Factors predicting outcomes}

Information regarding the outcomes of patients undergoing total pancreatectomy with islet autotransplantation (TPIAT) is limited primarily to retrospective case series which have demonstrated correlations between islet yield (in islet equivalents [IEQ] and islet equivalents per kilogram of recipient body weight $[\mathrm{IEQ} / \mathrm{kg}]$ ), lower body surface area (BSA $\left.\left[\mathrm{m}^{2}\right]\right)$, and female gender [4,6-8]. Large series have reported significantly higher islet yields in pediatric patients, possibly related to a decreased number of prior surgical interventions which are independently associated with higher rates of islet graft failure 1 year post-operatively [6].

*Corresponding author: Kenneth L. Brayman, M.D., Ph.D., Department of Surgery, University of Virginia Health System, Box 800709, 1215 Lee Street Charlottesville, 22908, Virginia, Tel: (434) 924-9370; Fax: (434) 924-5539; E-mail klb9r@virginia.edu

Received February 23, 2016; Accepted March 11, 2016; Published March 09, 2016

Citation: DeBolt CL, Jolissaint JS, Tatum JA, Strand DS, Wang AY, et al. (2016) Patient Demographics, Perioperative Testing, and Symptom Management in Total Pancreatectomy with Islet Autotransplantation. Surgery Curr Res 6: 264 doi:10.4172/2161-1076.1000264

Copyright: (C) 2016 DeBolt CL, et al. This is an open-access article distributed under the terms of the Creative Commons Attribution License, which permits unrestricted use, distribution, and reproduction in any medium, provided the original author and source are credited. 
Citation: DeBolt CL, Jolissaint JS, Tatum JA, Strand DS, Wang AY, et al. (2016) Patient Demographics, Perioperative Testing, and Symptom Management in Total Pancreatectomy with Islet Autotransplantation. Surgery Curr Res 6: 264. doi:10.4172/2161-1076.1000264

Page 2 of 3

\begin{tabular}{|c|c|c|c|c|c|}
\hline Group & Cincinnati [14] & Cleveland [12] & Baylor [11] & Minnesota [6] & Leicester [2] \\
\hline Follow up time & 5-years & Median of $27 \mathrm{mo}$. (3-66 mo.) & Mean of $23.7 \pm 2.2 \mathrm{mo}$. & 36 months & Median of 11.5 years \\
\hline Insulin Independence & $27 \%(n=15)$ & $33 \%(n=12)$ & $41 \%(n=51)$ & Approximately $20 \%$ & $19 \%(n=11)$ \\
\hline Narcotic Independence & $73 \%(n=41)$ & $53 \%(n=19)$ & Not reported & 70\% 1-year postoperatively & $45 \%(n=27)$ \\
\hline
\end{tabular}

Table 1: Outcomes after total pancreatectomy with islet autotransplantation (TPIAT).

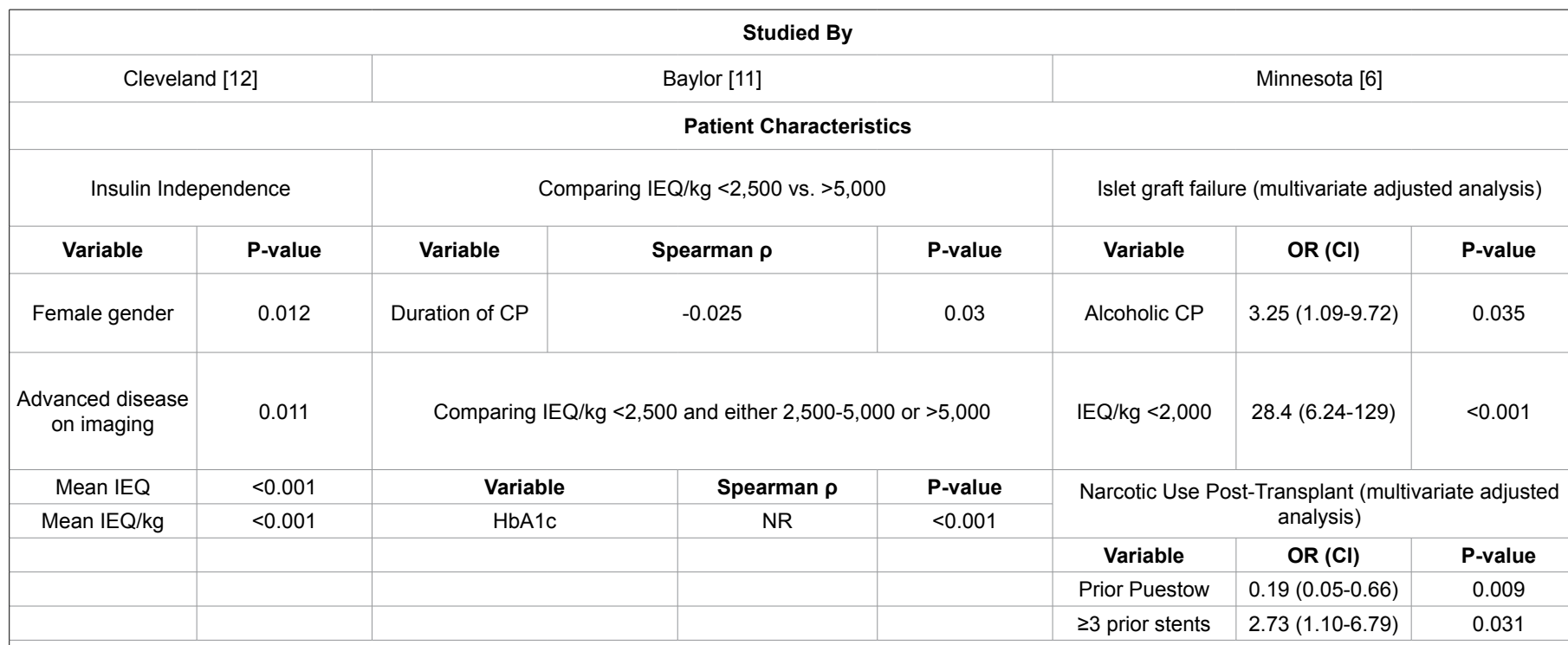

Abbreviations: $\mathrm{Cl}=$ confidence interval; $\mathrm{CP}=$ chronic pancreatitis; $\mathrm{DP}=$ distal pancreatectomy; $\mathrm{HbA} 1 \mathrm{c}=$ hemoglobin $\mathrm{A} 1 \mathrm{c}$; IEQ=islet equivalent; IEQ/kg=islet equivalent per kilogram patient body weight; $\mathrm{NR}=$ not reported; $\mathrm{OR}=$ odds ratio

Table 2: Factors predicting outcomes after total pancreatectomy with islet autotransplantation (TPIAT)

The etiology of $\mathrm{CP}$ is variably predictive, and patients with alcoholism or hereditary pancreatitis may have lower pancreas volumes, increased pancreatic structural changes, lower islet yields, and increased risk of islet graft failure, while those with idiopathic pancreatitis may have lower risks of islet graft failure [6,9,10]. Multiple studies have also demonstrated the relationship between longer disease duration and duration of narcotic use with low islet yield and graft failure (Table 2) [6,11]. Perhaps more subjectively, patients who reported more severely impaired physical health prior to surgery also had independently associated increased risk of islet graft failure and higher risk of impaired health at 1-year after TPIAT [6].

\section{Metabolic testing}

Metabolic testing prior to surgery is often performed to establish a preoperative baseline for islet function and data suggest fasting glucose levels $<100 \mathrm{mg} / \mathrm{dL}$, C-peptide $\geq 4 \mathrm{ng} / \mathrm{mL}$ are associated with higher islet yields, and hemoglobin A1c (HbAlc) and mixed meal tolerance tests (MMTTs) are inversely correlated with IEQ $/ \mathrm{kg}$ [10-12]. Moreover, fasting sample intravenous glucose tolerance testing (FSIVGTT) and MMTTs have been reported as significant predictors of islet mass $\geq 2500 \mathrm{IEQ} / \mathrm{kg}$ [10]. However, data is inconclusive and other studies have failed to identify significant correlations between total islet yield and perioperative with $\mathrm{HbA1c}$, C-peptide, or glucose levels $[13,14]$.

\section{Pre-operative imaging}

Pancreas weight and gross fibrosis are correlated with lower islet yield and both factors negatively impact islet mass, however, these features are usually only determined intra-operatively $[10,15]$. Preoperative imaging may be used to better predict islet function, IEQ yield, and post-operative outcomes. MRI and computerized tomography
(CT) scanning can generate 3-dimensional images of the pancreas and accurately calculate the volume of the pancreas, as well as assess for the presence of structural changes including: parenchymal calcifications, atrophy, and dilation of the main pancreatic duct. Islet yield has been understandably correlated with increased pancreatic mass, and mean islet yield has been reported to be decreased by $50 \%$ if any structural changes are demonstrated on imaging [9]. Calcifications in particular increase the odds of insulin dependence greatly, with only $15 \%$ of those with calcifications being insulin independent 1-year postoperatively [9]. Additionally, utilizing magnetic resonance imaging (MRI) and secretin-enhanced magnetic resonance cholangiopancreatography (SMRCP), features such as T1 signal-intensity ratio between the pancreas and paraspinal muscles and duodenal filling after secretin injection can accurately predict pancreatic fibrosis, islet mass, and subsequent islet yield $[10,16]$.

\section{Pancreatic enzyme replacement therapy (PERT)}

Although pancreatic enzyme replacement therapy (PERT) is routinely employed to counteract the loss of exocrine pancreatic function, patients continue to experience symptoms related to gastrointestinal malabsorption, including steatorrhea, weight loss, and glycemic variability. One study of 184 patients revealed that $80 \%$ of individuals reported diarrhea 1-year postoperatively and half felt that it interfered with their daily life [17]. In the same study, $72 \%$ of patients felt that their steatorrhea had increased significantly by 3 -years postoperatively, however, the use of pancreatic enzymes was only marginally associated with decreased likelihood of steatorrhea (OR 0.35, 95\% CI 0.12- 1.06, $p=0.055$ ) [17]. Additionally, there was no significant association between increased GI symptoms and decreased (self-reported) adherence to pancreatic enzyme replacement therapy (PERT) $(\mathrm{p}=0.7)[17]$. 
Citation: DeBolt CL, Jolissaint JS, Tatum JA, Strand DS, Wang AY, et al. (2016) Patient Demographics, Perioperative Testing, and Symptom Management in Total Pancreatectomy with Islet Autotransplantation. Surgery Curr Res 6: 264. doi:10.4172/2161-1076.1000264

\section{Discussion and Conclusions}

There are still many barriers that limit the utility and outcomes of TPIAT and only a few highly experienced centers available are available to perform the operation. Insurance companies are often reluctant to cover the costs of islet isolation and many physicians are unfamiliar with the procedure or post-operative anatomy, physiology, or imaging, thus requiring patients to return to the TPIAT center for care and potentially resulting in delayed or absent follow-up $[18,19]$.

Predictive factors suggest that when deciding on timing for TPIAT, delaying surgery is likely disadvantageous, as the duration of $\mathrm{CP}$ and worsening metabolic status are predictive of higher rates of graft failures and as more severely impaired patients are not likely to reach a normal state postoperatively. Factors suggestive of good outcomes should not necessarily limit patient selection but rather, should permit multidisciplinary health teams to assess candidacy and thereby provide appropriate pre-operative counseling and improved post-operative care, while still acknowledging and preparing for those at risk for poor outcomes.

Ultimately, TPIAT has proven benefit, with preservation of $\beta$-cell function and pancreas removal often resulting in insulin independence drastically improved QoL. However, there are still many questions to be addressed, including appropriate timing for TPIAT intervention, best practice for islet isolation and transplantation, and how to manage post-operative pain and gastrointestinal complications. With continued research into each facet of pre- and postoperative care, in addition to improved insight into optimal patient selection, TPIAT is a procedure adequately poised to address the $\mathrm{CP}$ as a societal healthcare burden and improve quality of life for patients.

\section{Disclosures}

Andrew Y. Wang, M.D., receives research support from Cook Medical regarding metal biliary stents

\section{References}

1. Yadav D, Lowenfels $A B(2013)$ The epidemiology of pancreatitis and pancreatic cancer. Gastroenterology 144: 1252-1261.

2. Garcea G, Pollar CA, Illouz S, Webb MB, Metcalfe MS, et al. (2013) Patient satisfaction and cost-effectiveness following total pancreatectomy with islet cell transplantation for chronic pancreatitis. Pancreas 42: 322-328.

3. Goulden (2013) MR The pain of chronic pancreatitis: a persistent clinical challenge. Br J Pain 7: 8-22.

4. Witkowski P, Savari O, Matthews JB (2014) Islet autotransplantation and tota pancreatectomy. Adv Surg 48: 223-33.

5. Najarian JS, Sutherland DE, Matas AJ, Steffes MW, Simmons RL, et al. (1977) Human islet transplantation: a preliminary report. Transplant Proc 9: 233-236.

6. Chinnakotla S, Beilman GJ, Dunn TB, Bellin MD, Freeman ML, et al. (2015) Factors predicting outcomes after a total pancreatectomy and islet autotransplantation lessons learned from over 500 cases. Ann Surg 262: 610-

7. Chinnakotla S, Bellin MD, Schwarzenberg SJ, Radosevich DM, Cook M, et al (2014) Total pancreatectomy and islet autotransplantation in children for chronic pancreatitis: indication, surgical techniques, postoperative management, and long-term outcomes. Ann Surg 260: 56-64.

8. Ahmad SA, Lowy AM, Wray CJ, D'Alessio D, Choe KA, et al. (2005) Factors associated with insulin and narcotic independence after islet autotransplantation in patients with severe chronic pancreatitis. J Am Coll Surg 201: 680-687.

9. Young MC, Theis JR, Hodges JS, Dunn TB, Pruett TL, et al. (2016) Preoperative Computerized Tomography and Magnetic Resonance Imaging of the Pancreas Predicts Pancreatic Mass and Functional Outcomes After Total Pancreatectomy and Islet Autotransplant. Pancreas

10. Lundberg R, Beilman GJ, Dunn TB, Pruett TL, Chinnakotla SC, et al. (2013) Metabolic assessment prior to total pancreatectomy and islet autotransplant: Utility, limitations and potential. Am J Transplant 2664-2671.

11. Takita M, Lara LF, Naziruddin B, Shahbazov R, Lawrence MC, et al. (2015) Effect of the duration of chronic pancreatitis on pancreas islet yield and metabolic outcome following islet autotransplantation. J Gastrointest Surg 19 : 1236-1246.

12. Johnston PC, Lin YK, Walsh RM, Bottino R, Stevens TK, et al. (2015) Factors associated with islet yield and insulin independence after total pancreatectomy and islet cell autotransplantation in patients with chronic pancreatitis utilizing off-site islet isolation: Cleveland Clinic experience. J Clin Endocrinol Metab 100: $1765-1770$

13. Khan KM, Desai CS, Kalb B, Patel C, Grigsby BM, et al. (2013) MRI prediction of islet yield for autologous transplantation after total pancreatectomy for chronic pancreatitis. Dig Dis Sci 58: 1116-1124.

14. Wilson GC, Sutton JM, Abbott DE, Smith MT, Lowy AM, et al. (2014) Long-term outcomes after total pancreatectomy and islet cell autotransplantation: Is it a durable operation? Ann Surg 260: 659-667.

15. Muratore S, Freeman M, Beilman G (2015) Total Pancreatectomy and Islet Auto Transplantation for Chronic Pancreatitis. Pancreapedia: Exocrine Pancreas Knowledge Base.

16. Trikudanathan G, Walker SP, Munigala S, Spilseth B, Malli A, et al. (2015) Diagnostic Performance of Contrast- Enhanced MRI with Secretin- Stimulated Non- Calcific Chronic Pancreatitis: A Comparison with Histopathology. Am J Gastroenterol. 110: 1598-1606.

17. Crosby J, Bellin MD, Radosevich DM, Chinnakotla S, Dunn TB, et al. (2015) Gastrointestinal symptoms before and after total pancreatectomy with islet autotransplantation: the role of pancreatic enzyme dosing and adherence. Pancreas 44: 453-458.

18. Robertson RP (2015) Total Pancreatectomy and Islet Autotransplantation for Chronic Pancreatitis: Breaking Down Barriers. J Clin Endocrinol Metab 100: 1762-1763.

19. Tai DS, Shen N, Szot GL, Posselt A, Feduska NJ, et al. (2015) Autologous Islet Transplantation With Remote Islet Isolation After Pancreas Resection for Chronic Pancreatitis. JAMA Surg 150: 118-124. 